\title{
A Hybrid Fuzzy Decision Making Procedure to Select among Outsourcing Alternatives for Waste of Electrical and Electronic Equipment
}

\author{
Melike Erdoğan, Yeşim Küçük, and İhsan Kaya
}

\begin{abstract}
In this paper, selection of outsourcing alternatives for waste of electrical and electronic equipment is performed with using fuzzy multi criteria decision making (MCDM) methodology. Related literature has been reviewed and the criteria are determined for evaluation. Five outsourcing firms are considered as alternatives for Istanbul Metropolitan Municipality and they are ranked according to the closeness coefficients that obtained by the proposed method. Finally the most appropriate outsourcing firm for waste of electrical and electronic equipment is determined for metropolitan municipality.
\end{abstract}

Index Terms-Fuzzy decision making, outsourcing, waste electrical and electronic equipment.

\section{INTRODUCTION}

One of the most important environmental problems in recent days is the increase of electrical and electronic waste quickly. These type of waste is not only become threat of environmental pollution, they also contain toxic substances which also a direct threat to human health. Apart from this high danger, electrical and electronic equipment waste has a high economic value. Namely, recycling electrical and electronic waste is not only to serve human health, but also contributes to the economic development.

Waste electrical and electronic equipment (WEEE), or e-waste, has recently attracted extensive attention as a secondary resource [1] and recovery of materials such as valuable metals contained in WEEE is currently popular in both developed and developing countries. At the same time, the hazardous nature of WEEE is also widely recognized [2], so WEEE is an important target for appropriate management for the prevention of environmental pollution. The waste of electrical and electronic materials can be described as all secondary computers and information technology equipment (printers, scanners, phone, fax machine etc.), entertainment device electronics, TV's, DVD's, toys, mobile phones, and other items such as refrigerators, lighting equipment, and medical devices, whether sold, donated, or discarded by their original owners and this definition includes used electronics which are destined for reuse, resale, salvage, recycling, or disposal [3]. The research generated by the UNEP (United Nations Environment Programme) [1] shows that the world will produce up to 50 million tons of WEEE per year. The

Manuscript received June 24, 2014; revised August 31, 2014.

The authors are with the Yildiz Technical University, Beşiktaş, İstanbul, 34349 Turkey (e-mail: melike@yildiz.edu.tr, yesim-kucuk@hotmail.com, ihkaya@yildiz.edu.tr.). current annual production of e-waste is 1.8 million tons in Germany, 1.5 million tons in France, and roughly 6 million tons in Europe [4]. Most of the developing countries do not have proper technology, formal government-driven or nongovernment-driven legislation, or EPR (Extended producer responsibility) program for WEEE management [4]. Quantities of used EEE are also extremely important to estimate potential the amount of WEEE for the upcoming years. In parallel with the technological developments in the world, consumption of electrical and electronic equipment is increasing in Turkey as well. According to a recent study [5], Turkey produces approximately 540.000 tonnes WEEE per year while WEEE per capita is more than 7 kilos. The majority of WEEE consists of generally TV and personal computers. With taken into consideration above results and that at least $50 \%$ of the production of EEE consists of only TVs for 2003-2007 and TVs have around 5 years typical lifelong [6]; the relevance between growth in the production of EEE and the increase of WEEE becomes obvious. Fig. 1 illustrates the production percentage of EEE in Turkey.

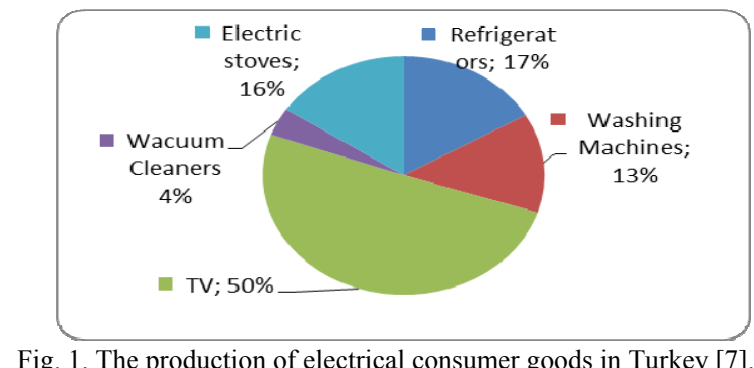

Institutions which produce more electrical and electronic equipment waste can be outsource these wastes to recycle or reuse of the materials. For example, for the public institutions, municipalities can have an agreement with outsourcing firms which brings is a great benefit for the collection of electronic waste.

As an example of this case, in this paper, we used a hybrid fuzzy multi criteria decision making method for selection of an outsourcing firm for the management of WEEE for İstanbul metropolitan Municipality. The fuzzy AHP method is used to obtain the criteria weights and fuzzy TOPSIS is used to rank the alternatives. The paper is organized as follows: The literature review of WEEE is detailed in Section II, Section III explains the fuzzy decision making methods used in this paper and presentation of suggested method. An application for selection of the most suitable outsourcing firm for the management of WEEE in Istanbul is presented in Section IV. Section V concludes the paper and gives future 
research suggestions.

\section{LITERATURE BACKGROUND}

The latest and newest papers about the topic can be summarized as follows: Kim et al. [8] presented Delphi-AHP modeling that can be used as a decision-making process tool in WEEE management. Li et al. [9] proposed a Particle Swarm Optimisation (PSO)-based selective disassembly planning method embedded with customizable decision making models and a novel generic constraint handling algorithm has been developed. With using multi-criteria and adaptive decision making models, they claimed their method is flexible to handle WEEE to meet the various requirements of stakeholders. According to Kiddee et al. [10], electronic waste (e-waste) is one of the fastest-growing pollution problems worldwide, several tools including Life Cycle Assessment (LCA), Material Flow Analysis (MFA), Multi Criteria Analysis (MCA) and Extended Producer Responsibility (EPR) have been developed to manage e-wastes. They expressed that using any one tool may be imperfect but in concert they can complement each other to solve this issue. Achillas et al. [11] proposed multicriteria optimization model for multi-type carriers of WEEE, based on multiple objective linear programming (MOLP). They claimed their approach minimizes total logistics costs, consumption of fossil fuel and production of emissions due to transportation of WEEE with the use of different types of containers. Kaya [12] presented an outsourcing decision for the management of WEEE by using a fuzzy multicriteria decision making approach. He proposed a methodology based on fuzzy group decision making approach to evaluate and to select the appropriate WEEE outsourcing firm in Istanbul, Turkey. Renteria et al. [13] proposed a new methodology for the selection and design of operations of a recycling system for electronic appliances, mainly television sets and monitors. Bereketli et al. [4] developed a linear programming technique for multidimensional analysis of preference (LINMAP) method for solving multi attribute group decision making (MAGDM) problems with preference information on alternatives in fuzzy environment for evaluation and select of a waste treatment strategy for EEE. They determined the best alternative as treating WEEE by using reuse and recycling methods. Kara [14] presented methodology integrates two multi-criteria decision methods to evaluate of outsourcing companies of waste electrical and electronic equipment recycling. Ciocoiu et al. [15] presented AHP for the evaluation of implementation of WEEE management systems. The proposed model was based on the analysis of political, economic, social, technical and environmental issues that may affect a successful implementation of WEEE management systems. The proposed model helped WEEE managers to understand more closely the decisive factors implied in the implementation of WEEE management systems. Pires et al. [16] integrated the AHP and the technique for order performance by similarity to ideal solution (TOPSIS) for alternative screening and ranking to help decision makers in a Portuguese waste management system. To underscore the role of uncertainty in decision making for alternative ranking, a fuzzy interval multi-attribute decision analysis was carried out to aid in environmental policy decisions. While AHP was used to determine the essential weighting factors, screening and ranking was carried out by TOPSIS under uncertainty expressed by using an interval-valued fuzzy (IVF) method.

\section{The Proposed Methodology}

In this paper, we proposed a fuzzy multi criteria decision making approach based on fuzzy AHP and fuzzy TOPSIS for selecting outsourcing firm in WEEE management. Buckley's [17] fuzzy AHP method is used to determine criteria weights and fuzzy TOPSIS is used to rank alternatives. The flow chart of our application is shown in Fig. 2.

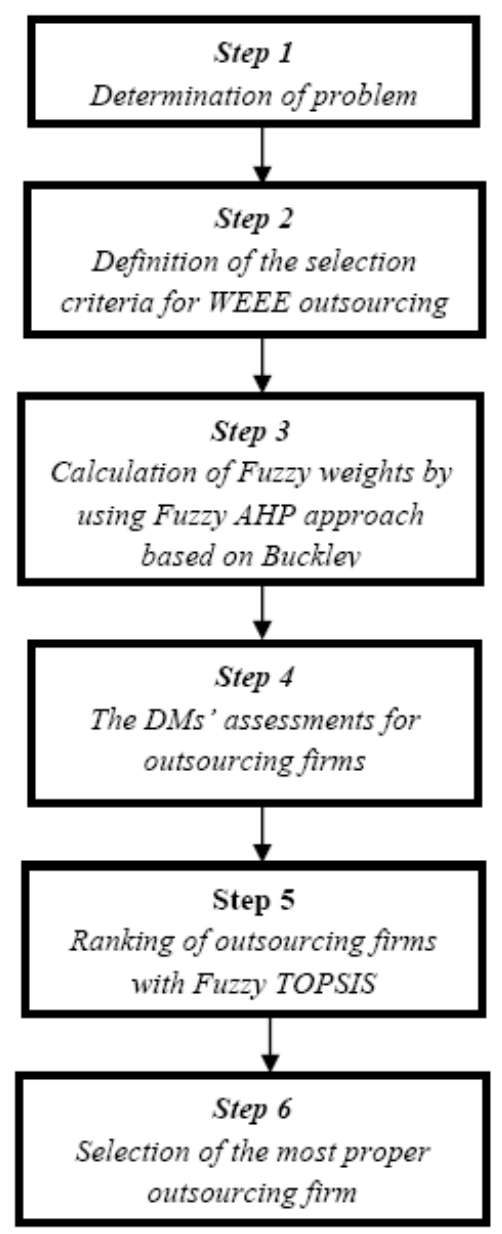

Fig. 2. The flow chart of the paper

The following subsections give information about the methods used in our methodology.

\section{A. Fuzzy AHP}

AHP is developed to solve complex MCDM problems involving multiple qualitative and quantitative criteria. It is very useful for handling multiple criteria and objectives in the decision-making problems. It allows decision-makers to specify their preferences using the Saaty's 1-9 scale [18]. This scale can be very useful in helping a group of experts or an individual to make a decision. The purpose of AHP is to provide weights for each criterion and alternatives. AHP requires three steps: (i) identifying evaluation criteria, (ii) assessing the decision-maker evaluations by pairwise comparisons, and (iii) calculating the weights for criteria and 
alternatives. In AHP, logical consistency is also considered by evaluating the validity of the pairwise comparison process obtained from decision-makers' preferences. Since the fuzzy set theory successfully represents human reasoning in its use of approximate information and uncertainty to generate decisions, the fuzzy-AHP methodology is used in this paper. In this paper, Buckley's [17] fuzzy AHP method is used. The steps of fuzzy AHP are summarized as following [19]-[22]:

Step 1. Pairwise comparison matrices are constructed. Each element $\left(\tilde{c}_{i j}\right)$ of the pairwise comparison matrix $(\mathrm{C})$ is a linguistic term representing the importance of one criterion over the other. The pairwise comparison matrix is given by;

$$
\tilde{C}_{k}=\left|\begin{array}{cccc}
1 & \tilde{c}_{12} & \ldots & \tilde{c}_{1 n} \\
\tilde{c}_{21} & 1 & \ldots & \tilde{c}_{2 n} \\
\vdots & \vdots & \vdots \vdots & \vdots \\
\tilde{c}_{n 1} & \tilde{c}_{n 2} & \ldots & 1
\end{array}\right|, k=1,2,3, \ldots, K
$$

where $\tilde{C}_{k}$ is a pairwise comparison matrix belongs to $k^{\text {th }}$ expert. For the evaluation procedure, the linguistic terms given in Table I [19] are used. Geometric mean is used to aggregate expert opinions.

TABLE I: LINGUISTIC SCALE FOR WEIGHT MATRIX

\begin{tabular}{|l|l|l|}
\hline Linguistic scales & Scale of fuzzy number & \\
\hline$(1,1,3)$ & Equally important & (Eq) \\
$(1,3,5)$ & Weakly important & (Wk) \\
$(3,5,7)$ & Essentially important & (Es) \\
$(5,7,9)$ & Very strongly important & (Vs) \\
$(7,9,9)$ & Absolutely important & (Ab) \\
\hline
\end{tabular}

Step 2. Weights are calculated. At first, the fuzzy weight matrix is calculated by Buckley's Method as follows;

$$
\begin{aligned}
& \tilde{r}_{i}=\left(\tilde{c}_{i 1} \otimes \tilde{c}_{i 2} \otimes \ldots \otimes \tilde{c}_{i n}\right)^{1 / n} \\
& \tilde{w}_{i}=\tilde{r}_{i} \otimes\left(\tilde{r}_{1}+\tilde{r}_{2}+\ldots+\tilde{r}_{n}\right)^{-1}
\end{aligned}
$$

where $\tilde{r}_{i}$ is the geometric mean of fuzzy comparison value and $\tilde{w}_{i}$ indicated by triangular fuzzy numbers $\tilde{w}_{i}\left(L_{i}, M_{i}, U_{i}\right)$ is fuzzy weight of $i^{\text {th }}$ criterion.

Step 3. After the fuzzy relative weight matrix is obtained, defuzzification process which converts a fuzzy number into a crisp value is utilized. In this paper, the total integral method is used for this aim. Liou and Wang [23] proposed the total integral value method with an index of optimism $\omega \in[0,1]$. Let $\tilde{A}$ be a fuzzy number with left membership function $f_{\tilde{A}}^{L}$ and right membership function $f_{\tilde{A}}^{R}$. Then the total integral value is defined as:

$$
E_{\omega}(\tilde{A})=\omega E_{R}(\tilde{A})+(1-\omega) E_{L}(\tilde{A})
$$

where

$$
\begin{aligned}
& E_{R}(\tilde{A})=\int_{\alpha}^{\beta} x f_{\tilde{A}}^{R}(x) d x \\
& E_{L}(\tilde{A})=\int_{\gamma}^{\delta} x f_{\tilde{A}}^{L}(x) d x
\end{aligned}
$$

where $-\infty<\alpha \leq \beta \leq \gamma \leq \delta<\infty$. For a triangular fuzzy number, $\tilde{A}=(a, b, c)$, the total integral value is obtained by

$$
E_{\omega}(\tilde{A})=\frac{1}{2}[\omega(a+b)+(1-\omega)(b+c)]
$$

\section{B. Fuzzy TOPSIS}

TOPSIS is a multi-criteria decision-making technique to rank different alternatives through numerical evaluations the decision maker performs with respect to certain criteria. Weights can also be specified for each criterion, in order to introduce a measure of the relative importance felt by the decision maker [24], [25]. The method is based on the consideration that the chosen alternative should have the shortest distance from the positive- ideal solution and the farthest distance from the negative ideal solution. TOPSIS defines an index called similarity to the positive- ideal solution and remoteness from the negative-ideal solution. Then the method chooses an alternative with the maximum similarity to the ideal solution [26]. The fuzzy set theory resembles human reasoning in its use of approximate information and uncertainty to generate decisions. It was specifically designed to mathematically represent uncertainty and vagueness and provide formalized tools for dealing with the imprecision intrinsic to many problems. By contrast, traditional computing demands precision down to each bit. Since knowledge can be expressed in a more natural way by using fuzzy sets, many engineering and decision problems can be greatly simplified. The decision maker can specify preferences in the form of natural language expressions about the importance of each criterion [20]. In this study fuzzy TOPSIS approach is used to specify the ranking of alternatives according to aggregated decision matrix and weight vector as well as the individual decision matrices and weigh vectors. Fuzzy TOPSIS (FTOPSIS) was first presented in [27], with reference to [28]. The basic principle of the fuzzy TOPSIS is that the chosen alternative should have the shortest distance from the positive ideal solution and the farthest distance from the negative-ideal solution in a geometrical (i.e., Euclidean) sense [28]. The steps of fuzzy TOPSIS can be summarized as follows [22], [29]:

Step 1. Form a committee of decision-makers, and then identify the evaluation criteria.

Step 2. Choose the appropriate linguistic variables for the importance weight of the criteria and the linguistic ratings for alternatives with respect to criteria. For this aim, Tables II and Table III can be used.

Step 3. Pool the decision makers' opinions to get the aggregated fuzzy rating $\tilde{x}_{i j}$ of alternative $A_{i}$ under criterion $C_{j}$ and aggregate the weights of criteria to get the aggregated fuzzy weight $\tilde{w}_{j}$ of criterion $C_{j}$ by using Eqs. (8) and (9), respectively.

$$
\begin{aligned}
& \tilde{x}_{i j}=\frac{1}{K}\left[\tilde{x}_{i j}^{1}(+) \tilde{x}_{i j}^{2}(+) \cdots(+) \tilde{x}_{i j}^{K}\right] \\
& \tilde{w}_{j}=\frac{1}{K}\left[\tilde{w}_{j}^{1}(+) \tilde{w}_{j}^{2}(+) \cdots(+) \tilde{w}_{j}^{K}\right]
\end{aligned}
$$

where $K$ is the number of decision makers, $\tilde{x}_{i j}^{K}$ and $\tilde{w}_{j}^{K}$ are 
the rating and the importance weight of the $K^{\text {th }}$ decision maker.

Step 4. Construct the fuzzy decision matrix and the normalized fuzzy decision matrix as in Eqs. (11) and (12).

$$
\begin{gathered}
\tilde{R}=\left[\tilde{r}_{i j}\right]_{m \times n} \\
\tilde{r}_{i j}=\left(\frac{a_{i j}}{c_{j}^{*}}, \frac{b_{i j}}{c_{j}^{*}}, \frac{c_{i j}^{*}}{c_{j}^{*}}\right), j \in B ; \\
\tilde{r}_{i j}=\left(\frac{a_{j}^{-}}{c_{i j}}, \frac{a_{j}^{-}}{b_{i j}}, \frac{a_{j}^{-}}{a_{i j}}\right), j \in C ; \\
c_{j}^{*}=\max _{i} c_{i j} \text { if } j \in B ; \\
a_{j}^{-}=\min _{i} a_{i j} \text { if } j \in C .
\end{gathered}
$$

where $B$ and $C$ are the set of benefit criteria and cost criteria, respectively.

TABLE II: LINGUISTIC VARIABLES FOR THE IMPORTANCE WEIGHT OF EACH CRITERION

\begin{tabular}{|l|l|}
\hline Very low (VL) & $(0.0,0.0,0.1)$ \\
\hline Low (L) & $(0.0,0.1,0.3)$ \\
\hline Medium low (ML) & $(0.1,0.3,0.5)$ \\
\hline Medium (M) & $(0.3,0.5,0.7)$ \\
\hline Medium high (MH) & $(0.5,0.7,0.9)$ \\
\hline High $(\mathrm{H})$ & $(0.7,0.9,1.0)$ \\
\hline Very high $(\mathrm{VH})$ & $(0.9,1.0,1.0)$ \\
\hline
\end{tabular}

TABLE III: LINGUISTIC VARIABLES FOR THE RATINGS

\begin{tabular}{|l|l|}
\hline Very poor (VP) & $(0,0,1)$ \\
\hline Poor $(\mathrm{P})$ & $(0,1,3)$ \\
\hline Medium poor (MP) & $(1,3,5)$ \\
\hline Fair $(\mathrm{F})$ & $(3,5,7)$ \\
\hline Medium good (MG) & $(5,7,9)$ \\
\hline Good (G) & $(7,9,10)$ \\
\hline Very good $(\mathrm{VG})$ & $(9,10,10)$ \\
\hline
\end{tabular}

Step 5. Construct the weighted normalized fuzzy decision matrix by Eqs. (13) and (14).

$$
\begin{aligned}
& \tilde{V}=\left[\tilde{v}_{i j}\right]_{m \times n} \\
& \tilde{v}_{i j}=\tilde{r}_{i j} \otimes \widetilde{w}_{j}
\end{aligned}
$$

Step 6. Determine FPIS and FNIS.

Step 7. Calculate the distances of each alternative from the fuzzy positive-ideal solution (FPIS, $A^{*}$ ) and the fuzzy negative-ideal solution (FNIS, $A-$ ) as in Eq. (15) and (16), respectively.

$$
\begin{aligned}
& A^{*}=\left(\tilde{v}_{1}^{*}, \tilde{v}_{2}^{*}, \ldots, \tilde{v}_{n}^{*}\right), \\
& A^{-}=\left(\tilde{v}_{1}^{-}, \tilde{v}_{2}^{-}, \ldots, \tilde{v}_{n}^{-}\right)
\end{aligned}
$$

Step 8. Calculate the distances to FNIS and PNIS

\begin{tabular}{|c|c|c|}
\hline Criteria & Sub-criteria & Weight \\
\hline \multirow{8}{*}{$\begin{array}{c}\text { Organization } \\
(0.134,0.31 \\
0.657)\end{array}$} & $\begin{array}{l}\text { Quality and quantity } \\
\text { of labor }\end{array}$ & $\begin{array}{l}(0.056,0.114, \\
0.252)\end{array}$ \\
\hline & $\begin{array}{l}\text { Degree of strategic } \\
\text { cooperation }\end{array}$ & $\begin{array}{l}(0.011,0.02 \\
0.044)\end{array}$ \\
\hline & Competitiveness & $\begin{array}{l}(0.013,0.022, \\
0.06)\end{array}$ \\
\hline & Experience & $\begin{array}{l}(0.183,0.368, \\
0.675)\end{array}$ \\
\hline & Financial performance & $\begin{array}{l}(0.016,0.034, \\
0.078)\end{array}$ \\
\hline & $\begin{array}{l}\text { Flexibility-Organizati } \\
\text { onal }\end{array}$ & $\begin{array}{l}(0.025,0.058, \\
0.112)\end{array}$ \\
\hline & Social responsibility & $\begin{array}{l}(0.078,0.159, \\
0.33)\end{array}$ \\
\hline & $\begin{array}{l}\text { Green process } \\
\text { planning }\end{array}$ & $\begin{array}{l}(0.111,0.225 \\
0.48)\end{array}$ \\
\hline \multirow{6}{*}{$\begin{array}{c}\text { Environment } \\
(0.2,0.44,0.968)\end{array}$} & $\begin{array}{l}\text { Environment-related } \\
\text { certificates }\end{array}$ & $\begin{array}{l}(0.057,0.14, \\
0.311)\end{array}$ \\
\hline & Air emissions & $\begin{array}{l}(0.041,0.11, \\
0.245)\end{array}$ \\
\hline & Waste water & $\begin{array}{l}(0.023,0.049, \\
0.132)\end{array}$ \\
\hline & Solid wastes & $\begin{array}{l}(0.115,0.271 \\
0.565)\end{array}$ \\
\hline & Energy consumption & $\begin{array}{l}(0.016,0.03, \\
0.069)\end{array}$ \\
\hline & $\begin{array}{l}\text { Use of harmful } \\
\text { materials }\end{array}$ & $(0.21,0.4,0.842)$ \\
\hline \multirow{4}{*}{$\begin{array}{c}\text { Cost } \\
(0.025,0.054 \\
0.139)\end{array}$} & Cost of collection & $\begin{array}{l}(0.064,0.19, \\
0.553)\end{array}$ \\
\hline & Cost of transportation & $\begin{array}{l}(0.048,0.114, \\
0.408)\end{array}$ \\
\hline & Cost of recycling & $\begin{array}{l}(0.133,0.376, \\
0.984)\end{array}$ \\
\hline & Cost of disposal & $\begin{array}{l}(0.101,0.32 \\
0.949)\end{array}$ \\
\hline \multirow{4}{*}{$\begin{array}{c}\text { Technology } \\
(0.049,0.105 \\
0.262)\end{array}$} & $\begin{array}{l}\text { Capacity and } \\
\text { technology level }\end{array}$ & $\begin{array}{l}(0.073,0.116, \\
0.238)\end{array}$ \\
\hline & Capability of R\&D & $\begin{array}{l}(0.037,0.066, \\
0.118)\end{array}$ \\
\hline & $\begin{array}{l}\text { Capability of } \\
\text { preventing pollution }\end{array}$ & $\begin{array}{l}(0.502,0.731, \\
0.988)\end{array}$ \\
\hline & $\begin{array}{l}\text { Flexibility-Technologi } \\
\text { cal }\end{array}$ & $\begin{array}{l}(0.055,0.087, \\
0.157)\end{array}$ \\
\hline \multirow{3}{*}{$\begin{array}{c}\text { Quality } \\
(0.037,0.091, \\
0.219)\end{array}$} & $\begin{array}{l}\text { Quality related } \\
\text { certificates }\end{array}$ & $\begin{array}{l}(0.082,0.212, \\
0.431)\end{array}$ \\
\hline & $\begin{array}{l}\text { Capability of process } \\
\text { quality }\end{array}$ & $\begin{array}{l}(0.182,0.402, \\
0.958)\end{array}$ \\
\hline & Reliability of process & $\begin{array}{l}0.178,0.386, \\
0.876)\end{array}$ \\
\hline
\end{tabular}
closeness coefficient of each alternative as in Eq. (17) and (18).

$$
\begin{gathered}
d_{i}^{*}=\sum_{j=1}^{n} d\left(\tilde{v}_{i j}, \tilde{v}_{i j}^{*}\right), i=1,2, \ldots, m \\
d_{i}^{-}=\sum_{j=1}^{n} d\left(\tilde{v}_{i j}, \tilde{v}_{i j}^{-}\right), i=1,2, \ldots, m
\end{gathered}
$$

where $d\left(d_{i}^{*}, d_{i}^{-}\right)$is the distance measurement between two fuzzy numbers.

TABLE IV: CRITERIA AND THEIR WEIGHTS

The closeness coefficients values.

Then a closeness coefficient is defined to determine the ranking order of all alternatives as in Eq. (19).

$$
C C_{i}=\frac{d_{i}^{-}}{d_{i}^{*}+d_{i}^{-}}, i=1,2, \ldots, m
$$

Step 9. According to the closeness coefficient, the ranking order of all alternatives can be determined.

\section{APPLICATION OF THE PROPOSED APPROACH}

In this paper, we aimed to determine an outsourcing firm alternative for the management of WEEE by using a hybrid fuzzy multi criteria decision making methodology that is 
based on AHP and TOPSIS for Istanbul Metropolitan Municipality (IMM) to make WEEE outsourcing and to select one outsourcing firm among five firms for the management of WEEE.

For this aim, IMM assign to 3 experts as DMs that 1 of them are employee at Department of Environmental Protection \& Development in IMM, one expert is a professor in Department of Industrial Engineering and the last one is a professor in Department of Environmental Engineering. The surveys are sent to experts to score the criteria reciprocally and alternatives separately. Before this, evaluation criteria and alternatives are determined. The criteria and sub-criteria have been determined with respect to related literature [12], [14], [30]-[32] and these experts' ideas can be shown in Table IV. Besides, Table IV shows the criteria weights obtained by fuzzy AHP process. To calculate criteria weights, only step 1 and 2 is used, and the first and second step of the TOPSIS is not used to determine the alternatives because they are already calculated with AHP. Alternatives are determined by IMM. Because of the privacy, the company names are not given.

According to fuzzy TOPSIS method, fuzzy decision matrix and normalized fuzzy decision matrix are constructed, FNIS and PNIS determined and the closeness coefficients for each alternatives are calculated. Closeness coefficients are shown in Table V.

TABLE V: THE OBTAINED CLOSENESS COEFFICIENT VALUES FOR

\begin{tabular}{|l|l|}
\hline \multicolumn{2}{|c|}{ ALTERNATIVES } \\
\hline $\mathrm{CC}_{\mathrm{A}}$ & 0.1025 \\
\hline $\mathrm{CC}_{\mathrm{B}}$ & 0.1021 \\
\hline $\mathrm{CC}_{\mathrm{C}}$ & 0.1068 \\
\hline $\mathrm{CC}_{\mathrm{D}}$ & 0.1032 \\
\hline $\mathrm{CC}_{\mathrm{E}}$ & 0.1020 \\
\hline
\end{tabular}

According to the hybrid methodology that we applied, we found alternatives " $C$ " is the best firm for outsource the waste of electrical and electronic equipment, and it is followed by firm " $D$ ". IMM should select firm $C$ to get more benefit in the view of organization, environment, cost, technology and quality aspects. Other companies should develop itself on the criteria specified in this paper.

When we analyze Table IV, we see that the most important main criterion in the evaluation process is "environment". This shows that in the recycling process of such waste, the most important factor is environmental protection. This criterion is followed by the organization that shows the structure of the company. This also means that firms should pay particular attention to these criteria to become more preferable by municipality. The main criterion in the last row is the cost criteria. This indicates that social and environmental aspects of this process much more important.

\section{CONCLUSION}

WEEE contains hazardous substances that are harmful to human health and contaminate the environment. Recycling of this type of waste is very important. For this perspective, the management of WEEE is one of the most serious problems in the world. Precautions should be taken at the municipality level. One of the important solutions for eliminating waste of electronic equipment can be accepted as finding an outsourcing firm to recycle and reusing processes. In this paper, we aim to find the most appropriate outsourcing firm with evaluating them many different criteria for İstanbul Metropolitan Municipality. For this aim, we proposed a hybrid methodology under fuzzy environment for management of WEEE for İstanbul metropolitan Municipality. The fuzzy AHP method is used to obtain the criteria weights and fuzzy TOPSIS is used to rank the alternatives. After an evaluating process we found the best alternative (outsourcing firm) for IMM. The most important factors in the evaluation process are also identified and some suggestions are made for firms.

As a final suggestion, trapezoidal fuzzy numbers can be used, different multi criteria decision making methodologies can be applied and sensitivity analysis can be conducted.

\section{REFERENCES}

[1] UNEP (United Nations Environmental Programme) Recycling-from e-waste to resources, 2009, Paris.

[2] O. Tsydenova and M. Bengtsson, "Chemical hazards associated with treatment of waste electrical and electronic equipment," Waste Management, vol. 31, pp. 45-58, 2011.

[3] M. Schlummer, A. Maurer, T. Leitner, and W. Spruzina, "Report: recycling of flame-retarded plastics from waste electric and electronic equipment (WEEE)," Waste Management and Research, vol. 24, pp. 573-83, 2006.

[4] İ. Bereketli, M. E. Genevois, Y. E. Albayrak, and M. Ozyol, "WEEE treatment strategies' evaluation using fuzzy LINMAP method," Expert Systems with Applications, vol. 38, pp. 71-79, 2011.

[5] Turkish Ministry of Environment and Urban Planning, 2012.

[6] B. H. Robinson, "E-waste: An assessment of global production and environmental impacts," Science of the Total Environment, vol. 408, pp. 183-191, 2009.

[7] TUIK,

[Online].

Available: http://www.library.illinois.edu/ias/iri/turkish/Turkey_Statistical_Year book 2008.pdf

[8] M. Kim, Y. C. Jang and S. Lee, "Application of delphi-AHP methods to select the priorities of WEEE for recycling in a waste management decision-making tool," Journal of Environmental Management, vol. 128, pp. 941-948.

[9] W. D. Li, K. Xia, L. Gao, and K. M Chao, "Selective disassembly planning for waste electrical and electronic equipment with case studies on liquid crystal displays," Robotics and Computer-Integrated Manufacturing, vol. 29, pp. 248-260, 2013.

[10] P. Kiddee, R. Naidu, and M. H. Wong, "Electronic waste management approaches: An overview," Waste Management, vol. 33, pp. 1237-1250, 2013.

[11] Ch. Achillas, D. Aidonis, C. Vlachokostas, N. Moussiopoulos, G. Banias, and D. Triantafillou, "A multi-objective decision-making model to select waste electrical and electronic equipment transportation media," Resources, Conservation and Recycling, vol. 66, pp. 76-84, 2012.

[12] İ. Kaya, "Evaluation of outsourcing alternatives under fuzzy environment for waste management," Resources, Conservation and Recycling, vol. 60, pp. 107-118, 2012.

[13] A. Renteria, E. Alvarez, J. Perez, and D. Del Pozo "A methodology to optimize the recycling process of WEEE: Case of television sets and monitors," International Journal of Advanced Manufacturing Technology, vol. 54, pp. 789-800, 2011.

[14] S. S. Kara, "Evaluation of outsourcing companies of waste electrical and electronic equipment recycling," International Journal of Environmental Science \& Technology, vol. 8, pp. 291-304, 2011.

[15] C. N. Ciocoiu, S. E. Colesca, and S. Burcea, "An AHP approach to evaluate the implementation of WEEE management systems," Recent Researches in Environment, Energy Planning and Pollution, pp. 233-238, 2011.

[16] A. Pires, N. B. Chang, and G. Martinho, "An AHP-based fuzzy interval TOPSIS assessment for sustainable expansion of the solid waste management system in Setúbal peninsula, portugal," Resources, Conservation and Recycling, vol. 56, pp. 7-21, 2011. 
[17] J. J. Buckley, "Fuzzy hierarchical analysis," Fuzzy Sets and Systems, vol. 17, pp. 233-247, 1985.

[18] T. L. Saaty, The Analytic Hierarchy Process, New York: McGraw Hill, 1980.

[19] T. Y. Hsieh, S. T. Lu, and G. H. Tzeng, "Fuzzy MCDM approach for planning and design tenders selection in public office buildings," International Journal of Project Management, vol. 22, pp. 573-584, 2004.

[20] C. Kahraman, U. Cebeci, and D. Ruan, "Multi-attribute comparison of catering service companies using fuzzy AHP: The case of Turkey," International Journal of Production Economics, vol. 87, pp. 171-184.

[21] C. Kahraman, A. Süder, and İ. Kaya, "Fuzzy multicriteria evaluation of health research investments," Technological and Economical Development of Economy, vol. 10, 2014.

[22] M. E. Baysal, İ. Kaya, C. Kahraman, A. Sarucan, and O. Engin, "A two phased fuzzy methodology for selection among municipal projects," Technological and Economic Development of Economy, vol. 20, pp. 31-48, 2013.

[23] T. S. Liou and M. J. Wang, Ranking fuzzy numbers with integral value," Fuzzy Sets and Systems, vol. 50, pp. 247-255, 1992.

[24] R. Gamberini, A. Grassi, and B. Rimini, "A new multi- objective heuristic algorithm for solving the stochastic assembly line re-balancing problem," International Journal of Production Economics, vol. 102, pp. 226- 243.

[25] C. Kahraman, O. Engin, O. Kabak, and I. Kaya, "Information systems outsourcing decisions using a group decision-making approach," Engineering Applications of Artificial Intelligence, vol. 22, pp. 832-841, 2009.

[26] K. P. Yoon and C. L. Hwang, Multiple attribute decision making: An introduction, Sage publications, 1995.

[27] S. J. Chen and H. C. Lai, Fuzzy Multiple Attribute Decision Making: Methods and Applications, Springer -Verlag- Berlin,1992.

[28] C. L. Hwang and K. Yoon, Multiple Attributes Decision Making Methods and Applications, Springer: Berlin Heidelberg, 1981.

[29] S. Aydın, C. Kahraman, and İ. Kaya, "A new fuzzy multicriteria decision making approach: an application for European quality award assessment," Knowledge Based Systems, vol. 32, pp. 37-46, 2012.
[30] A. H. I. Lee, H. Y. Kang, C. F. Hsu, and H. C. Hung, "A green supplier selection model for high-tech industry," Expert Systems with Applications, vol. 36, pp. 7917-7927, 2009.

[31] S. Y. Chiang, C. C. Wei, T. H. Chiang, and W. L. Chen, "How can electronics industries become green manufacturers in Taiwan and Japan," Clean Technologies and Environmental Policy, vol. 13, pp. 37-47, 2011.

[32] İ. Bereketli, T. Gürbüz, and M. G. Genevois, "A fuzzy multi-criteria approach to WEEE treatment strategy selection," in Proc. the IFSA6. EUSFLAT Conference, Lisbon, Portugal, July 20-24, 2009.

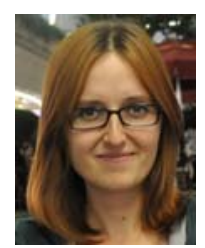

Melike Erdogan received a bachelor's degree from Anadolu University in the field of industrial engineering in 2011. She also received a master's degree in Yildiz Technical University on the same department in 2013. She is now continuing on her Ph.D. She is also a research assistant in Yildiz Technical University from 2012. She is studying for fuzzy logic and multi criteria decision making.

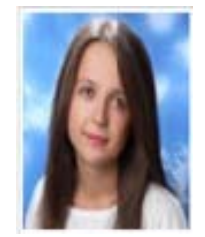

Yeşim Küçük received a bachelor's degree from Yildiz Technical University in the field of industrial engineering in 2013. She worked as an industrial engineering intern in BSH Turkey, Ernst \& Young, E.G.O. Turkey.

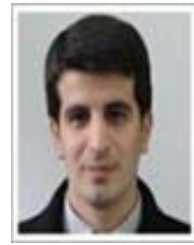

İhsan Kaya received BS and MSc degrees in industrial engineering from Selcuk University. He also received $\mathrm{PhD}$ degree from Istanbul Technical University on Industrial Engineering. He is currently an associate professor, at Yıldız Technical University at Departmen of Industrial Engineering. His main research interests include process capability analysis, quality management and control, statistical and multicriteria decision making, and fuzzy sets applications. 